
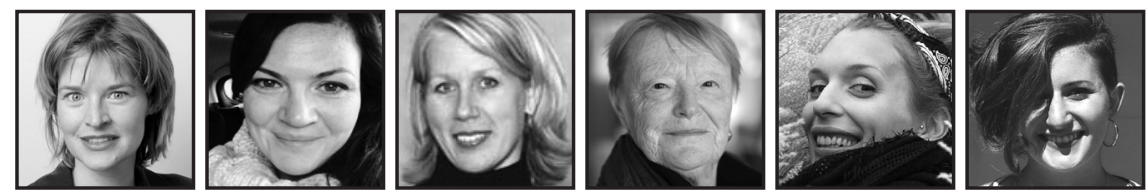

\title{
Building an Urban Arts Partnership Between School, Community-Based Artists, and University
}

\author{
Bronwen Low, Mindy R. Carter, Elizabeth Wood, Claudia Mitchell, \\ Melissa Proietti, and Debora Friedmann
}

\section{ABSTRACT}

This paper explores a partnership between a high school, university researchers, and community artists in the service of improved student learning, empowerment, and self-expression through the urban arts. The Urban Arts Project partners teachers at James Lyng high school with hip-hop and other urban artists to develop units across the curriculum, supported by subject-area specialists from McGill's Faculty of Education. In this article, we introduce the project and what we have learned about processes of school reform through cross-sectoral collaboration from the first year of our partnership. This includes sharing the perspectives of the teachers and artists most actively involved in the first year's initiatives (with video interview links).

This really was a catalyst, because the students who were already on board with math, okay, well this makes it slightly or much more interesting, but I was already on board with that. And the students who weren't on board really clicked with this, they clicked with him. He was able to reach students that I wasn't .... And they really, really did well. — Jake Roberts, math teacher

So we really bounced off each other really well and we were able to have this good chemistry that the kids saw and the kids appreciated as well. It wasn't just like I'm here and he's here, it was really like a team thing after that first week, once we got in motion with it all. - Turtlecaps, street artist 
he Urban Arts Project ${ }^{1}$ started from the supposition that if approximately
half of students do not graduate (in five years) from a high school,
and that many of those who do graduate do not pursue higher education, the onus is on the adults in the school and larger educational community to rethink how formal schooling works. Rather than assume that the problem lies with the students, we explore how to better meet the needs of students underserved by traditional school structures. What might a concerted group of actors from across sectors-school, university, and community-do together, and differently, in the interests of improving student engagement and learning at the secondary level? In this article, we ${ }^{2}$ introduce the Urban Arts Project (UAP) and what we have learned about processes of school reform through cross-sectoral collaboration from the first year of our partnership. More specifically, we will share the perspectives of the teachers and artists most actively involved in the first year's initiatives, including video interviews (https://drive.google.com/file/d/OB0OBo-icAo0zUEI3d2hPczFWYjA/view?).

\section{History of the Urban Arts Project}

In 2013, a group of McGill researchers in the Faculty of Education began conversations with the then principal of James Lyng High School (JLHS) about possibilities for collaboration in the interests of school transformation. The school is situated in St. Henri, a historically low-income and working-class neighborhood in the Southwest borough of Montreal. Over the years, the school's population has become increasingly diverse, from predominantly to minority white. That year, $78 \%$ of the students at JLHS had been coded or seen as at-risk of being coded with learning disabilities. In addition, the school has low enrollment rates (due to a complex of factors, including a declining population that is eligible to attend anglophone schools, the school's lack of a French immersion program, and a fairly negative reputation), which have meant that it has twice been threatened with closure in the past 10 years. In 2012/2013, less than half the students graduated. JLHS also had the highest rates of absenteeism and lateness in the English Montreal School Board. However, those statistics do not reflect the positive growth at the school, including a significant spike in participation in extracurricular activities, with more than half of students involved that year. Demonstrating a correlation between extracurricular engagement and school attendance, 70 percent of these participants achieved attendance awards. Some of the most popular of these extracurricular activities were connected to hip-hop or street art culture, including W.O.R.D., Writing Our Rhymes Down, a hip-hop literacy club that had been running beat-making and rap-writing workshops in the school for two years, and the 
Street Art Club, which brought in local street artists to collaborate with students on a range of projects including murals and more ephemeral genres such as wheat pasting, yarn bombing, pixel art, and green graffiti.

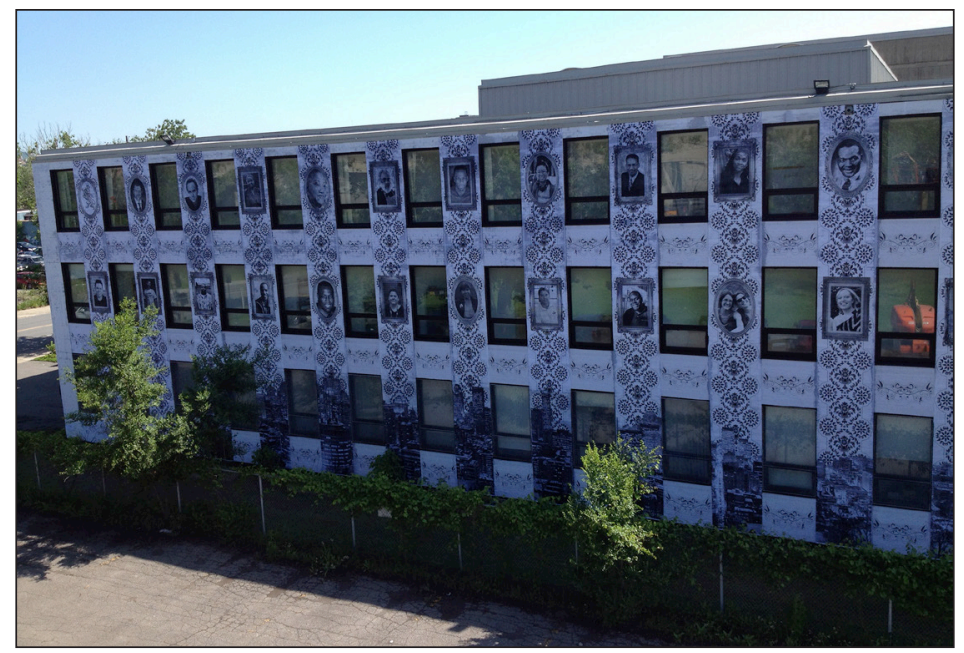

Fig. 1: Wheat paste mural (photo by Melissa Proietti)

Seeking to build on this evidence of student interest and to attract students from the neighborhood currently or considering attending schools outside the district, the school leadership committed to transforming itself into a school with a concentration in the "urban arts," in partnership with McGill and arts community members who had been actively involved in the life of the school. This meant taking an assets-based approach (Schorr, 1997) to school reform by building on student success, and integrating the urban arts across the curriculum; while extracurricular activities can be significant tools in helping students enjoy school more (Mahoney \& Cairns, 1997), they alone cannot adequately transform young people's experiences in school and so make a difference in their school achievement and life pathways.

We draw upon a capacious definition of the "urban arts," including aesthetic practices closely tied to, but also extending beyond, the art forms and values of hip-hop culture: rapping, DJing, street dance, and graffiti art, but also more recent forms such as hip-hop theatre, photography, journalism, and fashion (Chang, 2007). In its origins as a nonviolent and creative response to the experience of social and economic dispossession, hip-hop culture can promote creativity, self-knowledge, social entrepreneurship, and community building. Urban arts pedagogies tap into hip-hop's ethic of innovation and resourcefulness while expanding hip-hop's forms to include spoken-word poetry, muralism, graffic design, and other "street" art forms. 
Urban arts values, in our terms, include collaborative processes, listening and dialogue, community engagement and relevance, sustainability in urban contexts.

We work to transform the traditional school framework to include student-centered, arts-based curriculum strategies, fostering student engagement and learning. We also aim to empower and mobilize youth to access their voices within their own inner and outer school communities (Campbell, 2013; Prier, 2012). Our approach fosters both learning about the arts (developing competency in specific arts area) and learning through the arts (arts-based activities and skills integrated into another curricular area) (Krug \& Cohen-Evron, 2000), both well suited to building inclusive classrooms (Gerber \& Guay, 2006).

The UAP developed its principle objectives in the interests of sustainability, given the challenge of keeping initiatives going once the funding runs out (Foster, Reed, \& McGinnis, 2009). If the project is to make a meaningful and lasting impact, we need to focus primarily on professional development (PD) to build teacher capacities. This includes partnering teachers and artists to co-design and co-teach curriculum through and in relation to the urban arts, and offering PD that is sustained, cumulative, multi-dimensional, and tailored to individual teacher needs (Putnam \& Borko, 2000).

As part of our PD plan, we support teachers in developing practices of artsintegration, but also of culturally relevant pedagogy. Given the interests of JLHS students in the urban arts and our commitment to building bridges between school and community, the concepts of culturally relevant and responsive pedagogy (Villegas \& Lucas, 2002, Ladson-Billings, 1995) that access, assess, and draw upon student interests, skills, and "community sustaining" pedagogies (Paris, 2012), are central to our conceptual framework. We also draw upon Anti-Racist and Critical Race Theories to interrogate and resist race-related deficit models of youth and patterns of racerelated oppression (Dei, 2000; Ladson-Billings, 1998) that are so damaging and prevalent, especially given the disconnect between teaching populations which are predominantly white and school populations of racially marginalized youth, as found at JLHS and across North America (Ryan, Pollock, \& Antonelli, 2007). The second objective is to create an urban arts infrastructure, building urban arts events and spaces in the school to infuse the school culture with urban arts principles.

These objectives are accompanied by a research commitment to documenting, analyzing, and assessing the strengths and challenges of teacher and student experiences in integrating the urban arts at JLHS. In particular, we would like to better understand: how might the urban arts positively impact student engagement 
and learning? And, how to best support collaboration between artists and teachers in a university-school-community partnership? The three-way, mutually sustaining, partnership between school-university-community arts organizations significantly expands dominant school partnership models that generally involve school-university (Valli, Stefanski, \& Jacobson, 2014) and school-community collaborations (Sanders \& Harvey, 2002). Also innovative is the school's focus on the urban rather than traditional arts, and the presence of urban arts across the curriculum, for urban arts pedagogies and curricula are typically found in individual classroom units (Emdin, 2010; Hill, 2009; Low, 2011) or in informal programs. As well, hip-hop interventions in schools are usually based in rap writing, and not hip-hop dance and graffiti pedagogies.

\section{First Steps}

Some of the most tangible successes have been the creation of both a professional quality recording studio and a student-run art gallery. In its first few months, the studio supported projects from the music classroom and W.O.R.D. extracurricular activities, culminating in the production of a mix-tape showcasing raps and musical remixes as well as the school's new choir. The recording booths were painted by artists to look like Montreal STM metro cars.

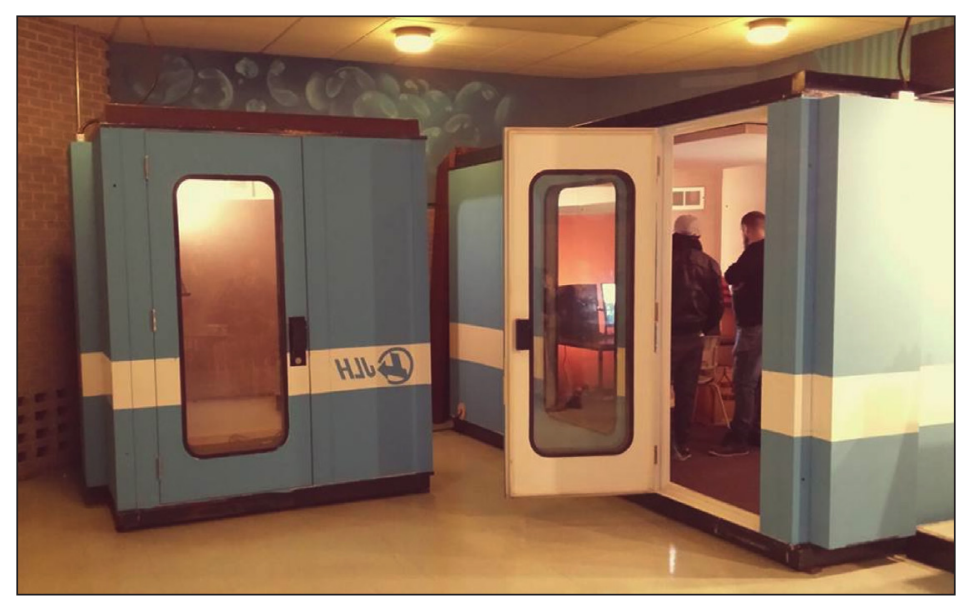

Fig. 2: JLHS recording studio (photo by Lou Piensa)

In turn, the UpNext art gallery hosted two student-curated art shows which received a tremendous amount of positive media attention. ${ }^{3}$ The gallery displays student artwork in tandem with that of professional artists, making clear that the school values their cultural production. The gallery also demonstrated very promising connections 
between student art curation and social engagement; the students chose to theme the first show, "The Struggle for Black Equality," held during Black History Month, and later curated "Skateboard Matters," featuring art works painted by students in the art class on blank skateboard decks, accompanied by a video sent to city officials lobbying for a new skate park. ${ }^{4}$ The school also had a studio classroom that we have turned into a space for students to practise and learn street dance styles through both extracurricular and in-class dance workshops.

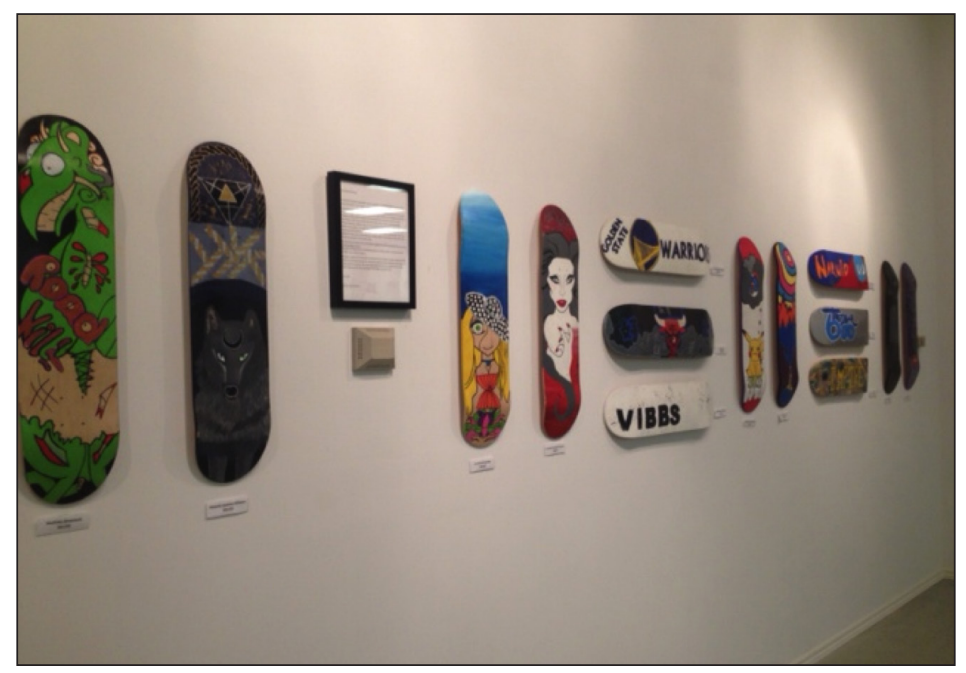

Fig. 3: Skateboard detail from gallery show

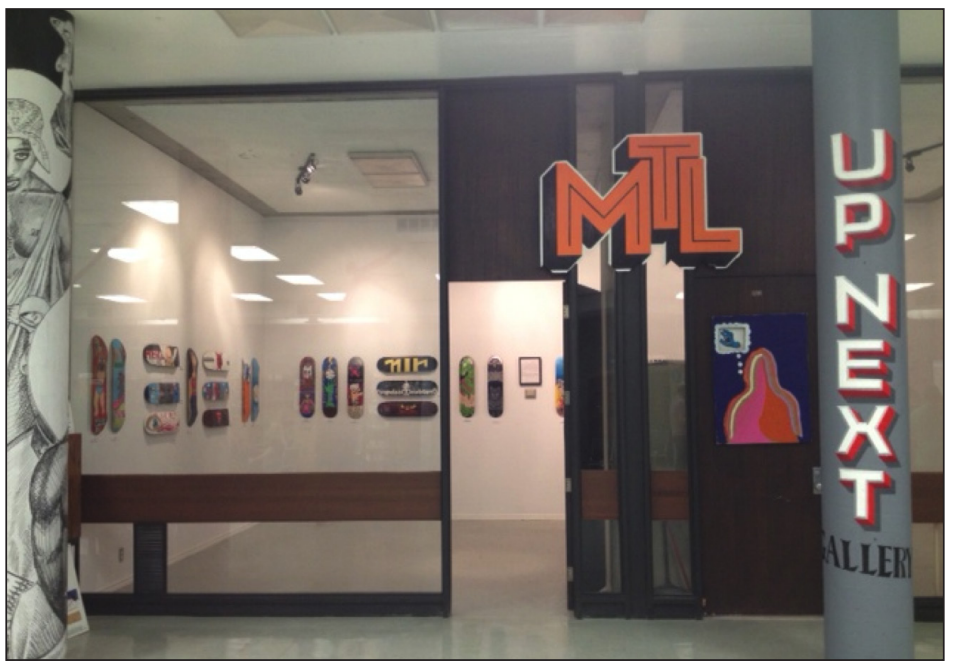

Fig. 4: UP NEXT Gallery (photos by Melissa Proietti) 
More complex has been the process of professional development, including the collaborations between artists and teachers. Year one of the funded project saw the development of a music program (electronic and instrumental) led by the newly hired music teacher, who worked closely with W.O.R.D. to integrate beat-making and production activities into his curriculum. In terms of urban arts curriculum development, there were artist-teacher collaborations in French, in which students learned to write and perform four rap bars (lines). As well, the new math teacher was very open to trying new things, and worked with street artist Turtlecaps to teach the concept of scale in relation to the process of mural creation (in which small designs are made big) and with a breakdancer called Skywalker in a geometry unit on the circle. Other related activities include the hip-hop fair organized by students in the 15+ program and the creation of a lunch hour street dance program.

\section{Insights}

From our observations-of professional development sessions, classroom units, and wider school events, interviews with participating artists and teachers throughout the year, and presentations by some teachers and artists at a conference in which they explored the collaborative process-we have initial insights into the dynamics, successes, and challenges of the project, a number of these related to the co-planning and co-teaching model between artists and teachers. ${ }^{5}$

\section{"Buy-in": Combatting stigmas around hip-hop culture and school culture.} Over the course of the project to date, we have learned a good deal about the complexities of partner "buy-in." Although the school initiated the collaboration with the university researchers as well as the urban arts focus, we have heard from teachers that they had not developed the vision with the school administration. As a result, a number of them have described the project as an imposition. For instance, one teacher shared that, "being completely honest, the urban art thing was kinda dropped on us." Given that researchers have demonstrated that teacher involvement in the conception of any comprehensive school reform initiative is crucial to project success (Desimone, 2000), this poses a challenge to the UAP, and helps explain why in the first year of the project, the most active participants were teachers in their first or second year at the school, informed of the urban arts program prior to joining the school community. As an example of the lack of widespread buy-in among the teaching staff, it seemed that some of the teachers had not attended either of the shows curated by students in the art-gallery, nor encouraged their students to attend. 
Not only were teachers not involved in envisioning the partnership and school focus on the urban arts, but also from comments made in professional development sessions, it seems that a number of them had reservations about a project connected with hip-hop, which they associated with its most commercial forms. As W.O.R.D. artist Butta Beats described,

urban arts gets framed as hip-hop, and there's a lot of stigma associated with hip-hop. They're like, oh, I don't know anything about that, so I don't want to be that chump being made fun of with the hippity hop. I think that can be scary, sometimes it's a generational thing, they just don't know its relevance.

Part of the challenge with these conversations is that hip-hop culture can be rife with lyrics that feature violence, misogyny, homophobia, and consumerism, an expression of some of the excesses of contemporary corporation-driven popular culture (Rose, 1994). In response, we have tried to allay some of these fears by introducing teachers to the nonviolent, grassroots history of hip-hop and to our commitment to developing critical perspectives with the students on hip-hop as well as culture more generally, by clarifying our concept of the "urban arts," which can include all art forms of interest to students. When some teachers noted that this was not a culture in which they had any expertise, we reassured them that the model was one of collaboration between artists and teachers, including a sharing of different forms of knowledge. Other concerns were that only a minority of the students were interested in hip-hop; however, subsequent student surveys done in Music and English class suggest that this is not the case.

Some of the tensions seem to be about changing aesthetics in the school. Through its partnership with the Under Pressure graffiti festival, the school inherited a number of street art works. 


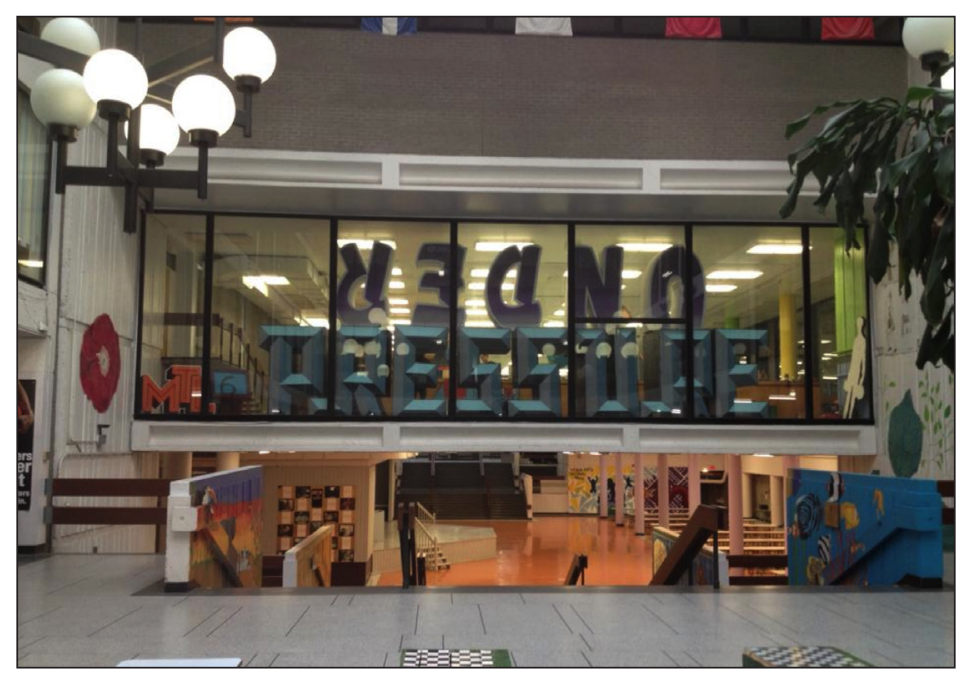

Fig. 5: Under Pressure logo in library (photo by Melissa Proietti)

One of these, a statue of Nina Simone as the Madonna made by underground and widely heralded street artist, Miss Me, was placed in the lobby of the school while the gallery was still under construction. This statue was moved several times, though no one came forward to say by whom and why. One day the statue disappeared, only to be discovered a few days later in a storage cupboard. We weren't certain whether or not to read this campaign as an act resistance against the urban arts initiative more generally, including its street art aesthetic.

In an interesting counterpoint, a number of the artists expressed reservations about working in schools. Along with Lou Piensa, W.O.R.D. teaching artist Butta Beats had been running rap music creation extracurricular activities at the school for several years. He has described the irony of finding himself working in a high school context, which he never enjoyed:

for me, honestly, high school was terrible in terms of my relationships. I didn't have a relationship with teachers. I found hip hop culture was a greater teacher, long term, in terms of my values, my core values for who I am as a person, hip hop was way more important than my high school.

While Butta's comments make clear the influence of hip-hop as an informal educational tool, they also suggest tensions between formal and informal education that the project needs to work through. For instance, it is a truism in education that most teachers (and university professors) enjoyed success in school, which can make it difficult for 
them to identify with and communicate with students who live school differently. Given a school culture in which many of the students do not see themselves as highachieving learners, the artists might better relate to student experience than some teachers. But might there be any adverse effects of bringing in artists with negative affective relations to schooling into the building?

This concern was raise by Jake, the math teacher. From the start, Jake had reservations about bringing an artist to his classroom, due to the complexities of co-teaching with someone you do not know well. As Jake tells it, his first meeting with Turtlecaps did not allay his concerns. Turtlecaps had described his negative memories of math as a student, explaining how,

I go home and I study it and I go back and I regurgitate it. Do I even understand it? Do I even remember any of this stuff? Probably not. Do I even care about it that much? Probably not. I just want to pass, you know? So that's what my math class was.

Of that exchange, Jake noted,

I should've probably taken this into account that his experiences learning math when he was a child himself were pretty negative, and that led him to have certain assumptions as to what happens in a math classroom. And so he came in and I think verbatim ... he more or less said, alright, so you're gonna take care of the boring, regular math stuff, and then I'm gonna come in and I'm gonna make it interesting for them, okay?

That said, both of their perspectives quickly changed through their interaction. On the first day of class, Turtlecaps openly expressed his support of both Jake and his math class to the students, a story Jake recounted like this:

And so one day he just stopped the class, and he said you don't understand, when I was in school, they'd let you sleep and they'd give you an F. Wake up! Wake up! And he was yelling at them and like, telling them how great I was, and I'm going like, yeah, that's the stuff. Can we do more of this urban arts stuff? This is so good! I had my own personal cheerleader, complete with this gravelly voice, and it was amazing.

The value of the artist as cultural broker. Part of the pedagogic value of Turtlecaps' open expression of enthusiasm for the math teacher and class lies in his negative history with formal education, shared with many of the students; in this way, he and the other artists act as powerful "cultural brokers" (Gay, 2000), helping to bridge cultural divides 
between students and school. These shared experiences include passions for the same pop cultural forms, including hip-hop. According to Butta Beats,

So the value we have as artists or as adult mentors, or greater peers that have a relationship to the culture that they already like anyways, and that we know a lot about, you can start having that dialogue and stuff. And then the kids start to open up a bit.

Some of that ability to broker lies in having hip-hop or street art experience, but also, other forms of cultural knowledge. As Butta Beats describes,

If the majority of the class is black, from a Caribbean background, and this is the first time you've met a kid from a black Caribbean background, you're in trouble, you're going to make all kinds of mistakes, and you're going to handle it so wrong.

Similarly, Turtlecaps shared that "my consciousness, a lot of it came from hip-hop culture as a value system." He adds that the students "relate to me a little bit better, just maybe even because of the color of my skin," identifying one of the significant effects of the cultural broker in our context, which is to reflect the racial identities of many of the students: "I think it's a challenge alone being a white teacher here to get kids' admiration and respect or even attention, you know. And like you have to build up a certain rapport with them in order to get that..." The UAP project has committed to bringing in as many artists of color as possible, and/or those who share similar cultural experiences with the students, including coming from surrounding neighborhoods, recognizing that the complexities of cultural knowledge and identification mean that racial representation alone is not sufficient in building bridges.

For Jake, Turtlecaps' ability to demonstrate the realities of being a professional street artist with a powerful work ethic and habits was also part of what made him an asset to the classroom. He described how his students will say,

I'm going to be a professional basketball player, I'm gonna be a skateboarder, I'm gonna be a graffiti artist, and they kind of say it like I'm going to do that instead of working hard, and I'm going to do that instead of your vision of success and it's like an escape, it's a departure.

In contrast, Jake explained that Turtlecaps was someone who 
was working way more than 40 hours a week, and it wasn't cushy 9 to 5 . I mean, it made what I do look really, really easy. And I think it was good for them to see that and he was role-modelling it.

The culture broker as positive role-model can be a powerful aspect of bringing artists into schools.

Centering student needs and interests. The UAP can also facilitate studentcentered pedagogies. This is in part because the extra adults in the classroom lower the student-teacher ratio. This was particularly important in Nathan Gage's music class, which he had originally structured around the Musical Futures program designed by music educator Lucy Green, in which students learn to play instruments by figuring out how to play songs in bands with their friends, in the informal manner by which many professional musicians learn. However, Nathan speculated that Green's students probably had more of a history of success in school, "a lot of self-confidence to overcome boundaries, to kind of meet obstacles and overcome those obstacles" and so were less likely to give up at early signs of failure than many of the students at JLHS. Therefore, while Nathan placed his students in bands, learning to play music they had chosen, they were also working in instrument specific groupings, taught by musicians, and given "direct instruction on their instrument that they could bring back to their groups."

Cornelia, a French teacher, also described how the artists allowed her to differentiate instruction, in that, "collaborating with the artist, our objectives were to blend our experiences together and to have the kids work on competencies that were adapted to their needs and come up with a product that they have ownership over." She shared how the collaboration allowed her to expand her pedagogical repertoire, giving her the "opportunity to open my classroom to new ideas and think outside the box of, you know, grammar." This experimentation has the potential to foster new kinds of relationships with students through their greater investment in class activities.

Another aspect of how the UAP can help foster student-centered pedagogies is in terms of student autonomy. Jake described how the arts-based curriculum increased his students' willingness to make choices about how they engaged the task, saying that,

It changed the conversation, it made them a lot more self-sufficient in learning math from that point onwards, because they're so used to-a few of them, especially the ones with a lot of learning difficulties-are used to constantly having to go see 
the teacher for more, and for help and, ... what do I now, and what do I do now, and what do I do now, and I said well, what do you think you should do now? Whoa.

Integrating the arts in the curriculum can allow the students to take greater ownership of their learning, shifting the balance from teacher to learner driven education.

The need for scaffolding collaboration. In the project's vision for the collaboration between artists and teachers, they would be sharing expertise, co-planning with the support of university content-area specialists, and then co-teaching. This has proven to be one of the biggest challenges for the project. The French teacher described how it was difficult for her to plan with the artists because she was in her first term at the school, and "was on survivor mode at the beginning, so it was hard to see, you know, what our objectives are." While they were able to come up with some simple objectives "geared towards what the students need," she recommended more planning. The teacher also did not schedule time to meet with the university second language specialist, largely due to being in survivor mode. The co-planning process was more successful in the math class, in which a few planning sessions were able to take place, supported by two university math educators. Here too, though, everyone felt that more time to plan would have been useful, though difficult, due to what Jake described as "the challenges of synchronizing the schedule of a multi-national street artist with the Quebec curriculum and math and my teaching commitments and etc., etc. It was a lot of moving pieces."

We have realized that better supporting the collaboration would be helpful to the artists too, as in the case of Hadi, a musician offering guitar instruction who, "felt like sometimes I was spending more time trying to figure out how to make every single student kind of participate." W.O.R.D. artist Lou Piensa reflected on the need for more time to co-plan and strategize with teachers, making the process more "efficient," because, "there was moments of chaos that I felt like we just were there but nothing was really happening that was related to them learning." The planning is particularly important because the artists might be, as Butta described, "real great creative people who don't teach," or at least, do not have any formal teaching experience.

The value of networks. A final lesson from our first year is of the importance of the networks and expertise of members of the UAP team. After months of researching how to build an affordable professional quality recording studio, Lou Piensa was able to source two secondhand booths from a local studio. Melissa Proietti, the head of the street art club and director of the Montreal Under Pressure hip-hop festival, was able to transform a fluorescent-lit, cinderblock-walled storage space in the school into a 
light and airy gallery for very little money, drawing upon her experience with Under Pressure's Fresh Paint gallery and her networks of willing contractors. Her multiple roles-hip-hop community member, research assistant, and well-known member of the school community - also meant that she was able to keep paths of communication open between the various sectors. Debora Friedmann was able to start (and study) street dance initiatives in the school through her own dance networks at the university and wider community. The new music teacher was also able to play a multi-faceted role in the project since he also taught the students in $15+$, a program for students currently below grade level that focuses on student entrepreneurship. This meant that he was able to explore some of the cross-curricular possibilities of the UAP in projects such as the multimedia Black Lives Matter art show that also included instrumental tracks created by the music students. Both the music and 15+ programs are more open-ended, less shaped by specific curricular content, which facilitates the creation of larger, integrative, arts-infused project-based learning. The task of supporting and researching school transformation seems to benefit from the synergy of members with established relationships at the school and various communities who can play multiple roles, as well as flexible spaces in the curriculum. This synergy also includes having different members of the project apply for grants across sectors.

As we move into the project's second year, we grapple with the challenges of transforming a school culture. Our next steps include shifting our focus towards teacherled professional development and maintaining a commitment to incorporating a range of art forms into the school culture, reflecting student needs and interests. We have seen tangible positive impacts of this work on the engagement, sense of ownership, and self-esteem of students who have participated at curricular and extracurricular levels. Urban arts pedagogies bolster student confidence by valuing student knowledge, and give students the space and opportunity to share that knowledge with their teachers, as well as with one another. As we revision our professional development through teacher-centered dissemination of knowledge, we also recognize the empowering process of student-centered peer teaching. We are also exploring changes to school structures, including the possibility of an advisory system which supports the development of personal learning profiles for each student, project-based learning, and strong connections with adults in the school.

Though making meaningful and sustainable change in the school is a complex process, our pilot year has highlighted many of the innovative and meaningful pedagogical aspects of urban arts. In the spirit of these art forms, we value fluidity and continual evolution in our processes, encouraging educators to "remix" their methods and styles of teaching with those of the hip-hop community of Montreal. We aim to 
resist static modes of education that focus on a limited definition of achievement by exploring definitions of learning and success that emerge organically through innovations and reformulation led by students, teachers, and artists. Our challenge is to continue to think as creatively as possible about what a school that best meets the needs of its students might look and feel like.

\section{Acknowledgments}

We would like to thank the participating teachers and artists for the generosity of time and insight; and Michael Lipset for video editing.

\section{Notes}

1. This research stems from the SSHRC funded-study, "The urban arts as tool for transforming a disadvantaged high-school: Building partnership synergy between school, university, and community artists" (SSHRC Partnership Development Grant: principal investigator Bronwen Low, co-investigators Mindy Carter, Elizabeth Wood, and Claudia Mitchell).

2. While the UAP is a collaboration between administrators, teachers, artists, and researchers (represented on the project's various steering committees), the research is led by the McGill team, including the graduate research assistants, two of whom are co-authors of this paper. As members of the Montreal urban arts community, and in the case of one RA, a member of the school's board of governors, they help blur the divisions between school, community, and university.

3. http://www.cbc.ca/news/canada/montreal/james-lyng-skateboard-art-1.3598549; http://montreal.ctvnews.ca/video?clipld=816686\&binld=1.1332485\&playlist PageNum=1\#_gus\&_gucid=\&_gup=Facebook\&_gsc=axECJkS; http://montrealgazette.com/opinion/columnists/column-its-bigger-than-hip-hopits-high-school.

4. For more on the UpNext gallery, see the video interview with Melissa Proietti, http:// www.learninglandscapes.ca/rich-media/136-melissa-proietti-video.

5. Teacher and artist identities will be masked to preserve confidentiality, except for the teachers and artists who have chosen to be videotaped. 


\section{References}

Campbell, M. (2013). Out of the basement: Youth cultural production in practice and in policy. Montreal, QC: McGill-Queen's University Press.

Chang, J. (2007). Can't stop, won't stop: A history of the hip-hop generation (4th ed.). London: Ebury Press.

Dei, G. (2000). Towards an anti-racism discursive framework. In G. Dei and A. Calliste (eds.) Power, knowledge and anti-racism education: A critical reader (pp. 23-29). Halifax, NS: Fernwood.

Desimone, L. (2000). The role of teachers in urban school reform. Making comprehensive school reform work. ERIC/CUE Digest Number 154. ERIC Clearinghouse on Urban Education.

Emdin, C. (2010). "Affiliation and alienation: Hip-hop, rap, and urban science education." Journal of Curriculum Studies, 42(1), 1-25.

Foster, K., Reed, H., \& McGinnis, K. (2009). After the funding flees: A how-to model for sustaining the professional development school partnership. School-University Partnerships, 3(1), 113-118.

Gay, G. (2000). Culturally responsive teaching: Theory, research, and practice. New York: Teachers College Press.

Gaztambide-Fernandez R.A., Saifer A., \& Desai, C. (2013). "Talent and the misrecognition of social advantage in specialized arts Education." Roeper Review, 35(2), 124-135.

Gerber, B. L., \& Guay, D. M. (Eds.). (2006). Reaching and teaching students with special needs through art. Reston, VA: National Art Education Association.

Goldberg, M. (2012). Arts integration (4th ed.). Boston: Pearson Inc.

Hill, M. L. (2009). Beats, rhymes, and classroom life: Hip-hop pedagogy and the politics of identity. New York: Teachers College Press.

Krug, D.H., \& Cohen-Evron, N. (2000). Curriculum integration positions and practices in art education. Studies in Art Education, 41(3), 258-275.
Ladson-Billings, G. (1995). But that's just good teaching!: The case for culturally relevant pedagogy. Columbus, $\mathrm{OH}$ : Ohio State University

Ladson-Billings, G. (1998). Just what is critical race theory and what's it doing in a 'nice' field like education. International Journal of Qualitative Studies in Education, 11(1), 7-30.

Low, B. (2011). Slam school: Learning through conflict in the hip-hop and spoken word classroom. Stanford, CA: Stanford University Press.

Mahoney, J. L., \& Cairns, R. B. (1997). Do extracurricular activities protect against early school dropout? Developmental Psychology, 33, 241-253.

Miller, P. M., \& Hafner, M. M. (2008). Moving toward dialogical collaboration: A critical examination of a university-schoolcommunity Partnership. Educational Administration Quarterly, 44(1), 66-110.

Mitchell, C., Weber, S.J., \& O'Reilly-Scanlon, K. (Eds.). (2005). Just who do we think we are? Abingdon, England: Routledge Falmer.

Moll, L. (1992). Funds of knowledge for teaching: Using a qualitative approach to connect homes and classrooms. Theory Into Practice, 31(2), 132-141.

Paris, D. (2012). Culturally sustaining pedagogy: A needed change in stance, terminology, and practice. Educational Researcher, 41(93), 93-97.

Prier, D. (2012). Culturally relevant teaching: Hip hop pedagogy in urban schools. New York: Peter Lang Publishing.

Putnam, R., \& Borko, H. (2000). What do new views of knowledge and thinking have to say about research on teacher learning? Educational Researcher, 29(1), 4-15.

Rose, T. (1994). Black noise: Rap music and black culture in contemporary America. Middletown, CT: Wesleyan University Press 
Ryan, J., Pollock, K., \& Antonelli, F. (May, 2007). Unpublished conference paper. Teacher and administrator diversity in Canada: Leaky pipelines, bottlenecks and glass ceilings. Paper prepared for the Annual Conference of the Society for the Study of Education. Saskatoon.

Sanders, M., \& Harvey, A. (2002). Beyond the school walls: A case study of principal leadership for school-community Collaboration. The Teachers College Record, 104(7), 1345-1368.
Schorr, L. B. (1997). Common purpose. New York: Anchor Books

Valli, L., Stefanski, A., \& Jacobson, R. (2014). Typologizing school-community partnerships: A framework for analysis and action. Urban Education, on-line first, 1-29. doi:10.1177/0042085914549366.

Villegas, A. M., \& Lucas. T. (2002). Educating culturally responsive teachers: A coherent approach. Albany, NY: SUNY Press.

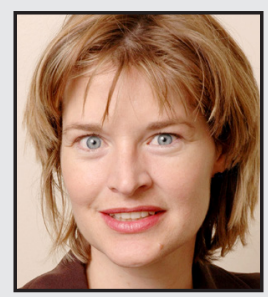

Bronwen Low is Associate Professor in the Department of Integrated Studies in Education in McGill University's Faculty of Education. Her research interests include the implications and challenges of popular youth culture for curriculum theory, literacy studies, and pedagogy; community-media projects and pedagogies; translanguaging and the multilingual Montreal hip-hop scene; and the pedagogical implications of the lifestories of Montrealers who have survived genocide and other human rights violations. Her books include "Slam school: Learning through conflict in the hip-hop and spoken word classroom" (Stanford UP, 2011), and the forthcoming "Community-based Media Pedagogies: Listening in the Commons" (in press), with Chloe Brushwood Rose and Paula Salvio. 


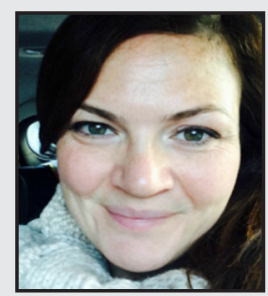

Mindy R. Carter, PhD is Assistant Professor in the Department of Integrated Studies in Education at McGill University. Her areas of interest include teacher identity, teacher education, drama and theatre education, outdoor education, arts based educational research and curriculum theory. Her first book, "The Teacher Monologues: Exploring the Identities and Experiences of Artist Teachers," was published by Sense in 2014 and her second book, "Drama, Theatre and Performance Education: Classroom and Community Contexts" (Coedited with Monica Prendergast and George Belliveau) came out in 2015. She is currently the President of the ARTS special interest group for The Canadian Society for the Study of Education.

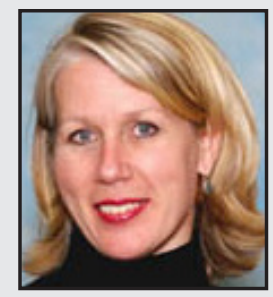

Elizabeth Wood is the Associate Dean, Academic Programs at McGill University. She is responsible for the governance of academic programs across the Faculty, and coordinates and facilitates the monitoring, evaluation, and development of programs. Dr. Wood is a member of the Department of Integrated Studies in Education. Her areas of teaching and research include teacher education, philosophy of education, arts education, and social justice education. 


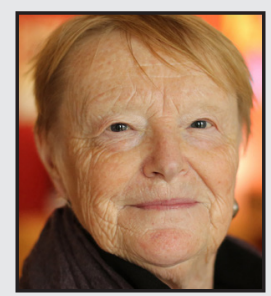

Claudia Mitchell, PhD, FRSC is a James McGill Professor in the Faculty of Education, McGill University, Montreal, and the Director of the Institute for Human Development and Well-being. Her research cuts across visual and other participatory methodologies in relation to youth and sexuality, girls' education, teacher identity, and critical areas of international development linked to gender and HIV and AIDS. In support of this work, she initiated the establishment of two research units, the Participatory Cultures Lab at McGill and the Centre for Visual Methodologies for Social Change at the University of KwaZulu-Natal. She is the Editor-in-Chief of Girlhood Studies: An Interdisciplinary Journal.

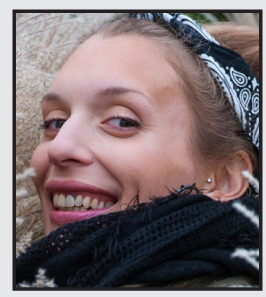

Melissa Proietti is a PhD student at McGill University in the Department of Integrated Studies in Education and has been working in formal and informal educational contexts for nearly 15 years with a wide range of learners. Based on organizational involvement with Under Pressure International Graffiti Convention and with the urban arts culture in Montreal, during her Masters she began to research the implementation of an urban arts program in a school as a method to encourage student engagement and success. This has carried on into her doctoral research which documents the development of the visual urban arts within the context of a wider shift in a school's development as it becomes the first urban arts concentration school in Canada. 


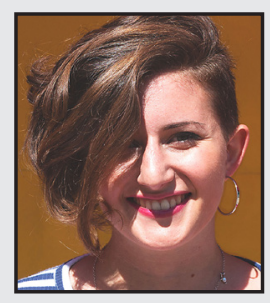

Debora Friedmann completed her BA in anthropology from McGill University in 2015 and is currently pursuing an MA in Education and Society. Research interests include: urban arts, dance in education, gender, secondary school education, and embodied knowledge. Aside from her research in an urban arts high-school, Debora choreographs theatre productions with postsecondary student groups and dances with LPP and Lockunity dance collectives in Montreal. 